\title{
Effects of Alien Substitutions of Chromosomes of Homoeologous Group 7 on the Heading Time of Wheat-barley Substitution Lines (Triticum aestivum L. - Hordeum marinum ssp. gussoneanum $4 x$ Hudson)
}

\author{
E.V. Chumanova, T.T. Efremova*, N.V. Trubacheeva and L.A. Pershina \\ The Federal Research Center Institute of Cytology and Genetics, Siberian Branch, \\ Russian Academy of Sciences, Novosibirsk, 630090 \\ (Received 11 July 2018; Accepted 30 October 2018; \\ Communicated by M. Molnár-Láng)
}

\begin{abstract}
The effects of alien substitutions of chromosomes on the heading time of ditelosomic (DT) wheat-barley substitution lines in which the chromosome $7 \mathrm{HL}^{\mathrm{mar}}$ from Hordeum marinum ssp. gussoneanum $4 x$ replaced the chromosomes 7A, 7B and 7D of common wheat were studied. The plants were grown under short and long day illumination in greenhouse and in the field. The lines studied were found to differ in response to the length of the day. Under short day conditions, DT7HL ${ }^{\operatorname{mar}}(7 \mathrm{~B})$ and DT7HL ${ }^{\operatorname{mar}}(7 \mathrm{~A})$ showed an increase in the period before heading. In this case, the substitution effect of chromosome $7 \mathrm{~B}$ was more significant than the effect of chromosome 7A. Under these conditions, the substitution of chromosome 7D did not have a significant effect on the heading time. Under long day conditions in the greenhouse and under natural conditions of a long day in the Novosibirsk region, substitution lines came into ear earlier than under a short day conditions and did not differ in the heading time. Allele-specific primers established the allelic composition of the genes $V r n-A 1$, $V r n-B 1, V r n-D 1$ and $V r n-B 3$ in ditelosomic lines. It was shown that the two DT7HL ${ }^{\operatorname{mar}}(7 \mathrm{~A})$ and DT7HL ${ }^{\operatorname{mar}}(7 \mathrm{D})$ lines have the same genotype -VRN-A1b/VRN-B1c/vrn-D1/vrn-B3 and that the DT7HL ${ }^{\operatorname{mar}}(7 \mathrm{~B})$ line has the genotype $-V R N-A 1 a / V R N-B 1 c / v r n-D 1$. The results show that regardless of the genotype for the $V r n$ genes, the wheat-barley substitution lines react to the change in the photoperiod, especially in the absence of chromosomes 7B and 7A.
\end{abstract}

Keywords: barley, Hordeum marinum $4 x$, wheat-barley substitution lines, ear emergence time, photoperiod genes, vernalization genes

\section{Introduction}

The duration of the growing season, including the heading time of cereals, is the most important agronomical trait determining the adaptation of cereals to specific growing conditions. An example of wide adaptation is the division of common wheat into spring and winter growth habits, depending on the genes involved in the sensitivity to vernalization $(V r n)$, which regulate and initiate the beginning of the reproductive development of plants.

*Corresponding author; E-mail: efremova@bionet.nsc.ru 
Sensitivity to the length of the day (photoperiod) is another example of the adaptability of common wheat, through which plants grow in regions with different day lengths. The plants sensitive to photoperiod develop faster with a long day, but with a shortening of the length of the day, they slow down development; the plants insensitive to the photoperiod develop rapidly both in the long and short days. This insensitivity to the duration of the light period is especially important for countries in which wheat yields more than one crop per year. It is considered that insensitivity to photoperiod dominates sensitivity (Law et al. 1978; Worland et al. 1998).

It has been established that the chromosomes of wheat and related species of homoeologous group 2, 5 and 7 carry genes that determine the sensitivity to vernalization ( Vrn) and the length of the day (Ppd). In wheat (Triticum aestivum L.), the genes for vernalization requirement $V r n-A 1, V r n-B 1$ and $V r n-D 1$ are located on the homoeologous group 5 chromosomes (Law et al. 1976; Snape et al. 1985), Vrn-D4 on chromosome 5D (Yoshida et al. 2010) and Vrn-B3 in chromosome 7BS (Yan et al. 2006). Photoperiod sensitivity genes $P p d-A 1, P p d-B 1$ and $P p d-D 1$ are localized on chromosomes of homoeologous group 2 (Law et al. 1978; Snape et al. 2001). The potency of the insensitivity of these genes has been ranked in the order of Ppd-D1 >Ppd-B1 >Ppd-A1 (Worland et al. 1998). The second homoeoallelic set of genes for photoperiod response is located on wheat chromosomes 7AS and 7BS (Kuchel et al. 2006). The Ppd-B2 gene, mapped on the short arm of 7BS, accelerates the heading time in a long day (Khlestkina et al. 2009).

Different mutations in the promoter or in the first intron of the $V r n-A 1$ gene have been described (Yan et al. 2004; Fu et al. 2005), and five dominant alleles have been designated Vrn-Ala, Vrn-A1b, Vrn-Alc, Vrn-Ald and Vrn-Ale. At least three mutant alleles of the dominant $V r n-B 1$ gene have been identified (Fu et al. 2005; Scherban et al. 2012). The $V r n-D 1$ gene possesses two alleles, Vrn-Dla and Vrn-D1b (Fu et al. 2005; Zhang et al. 2012). The dominant alleles of the genes Ppd-Ala, Ppd-Bla and Ppd-DIa confer the insensitivity of wheat to day length, while the recessive alleles (Ppd-A1b, Ppd-B1b and Ppd-D1b) confer sensitivity (Beales et al. 2007; Guo et al. 2010; Cane et al. 2013). Diagnostic DNA markers have been developed to identify the alleles of the VRN1 and PPD1 genes (Yan et al. 2004; Fu et al. 2005; Beales et al. 2007).

One method of genetic analysis that allows studying genes controlling important agronomical traits in wheat is the method of substitution of individual chromosomes (Law 1972; Ceoloni and Jauhar 2006; Qi et al. 2007). In genetic studies using lines with intervarietal and alien substitutions of chromosomes of homoeologous groups 2 and 5, the effects of these chromosomes on heading time and growth habits were studied (Law et al. 1976; Law and Worland 1997; Worland et al. 1998). Thus, as a result of the investigation of lines with intercultivar substitutions of chromosomes 5A and 5B from different donor cultivars, the presence of multiple alleles of the $V r n-A 1$ and $V r n-B 1$ loci was shown (Law et al. 1976; Snape et al. 1985; Efremova et al. 2011). It was shown that spring wheat (Snape et al. 1985) was obtained by replacing the 5A chromosome of the Hobbit winter cultivar with chromosome 5A Triticum spelta L., which carries the Vrn-A1 gene. When replacing the 5A chromosome of spring wheat cultivars Rang and Mironovskaya Krupnozernaya with chromosome $5 \mathrm{R}$ of rye $(S$. cereale) Onokhoiskaya with recessive allele 
$v r n-R 1$, it was possible to obtain winter wheat-rye substituted lines (Efremova et al. 2006). Law et al. (1978) studied the effect of homoeologous group 2 chromosomes on the response to day length based on lines with the alien substitution of $2 \mathrm{M}$ chromosomes from Aegilops comosa, $2 \mathrm{C}^{\mathrm{u}}$ from Ae. umbellulata and $2 \mathrm{R}^{\mathrm{m}}$ from $S$. montanum. Using wheat-barley (T. aestivum-H. vulgare) addition lines, the influence of barley chromosomes 5H (Murai et al. 1997), 4H and 7H on heading time under different conditions (Farkas et al. 2014) was established.

Thus, directed alien substitution of certain wheat chromosomes from different types of cereals allows us to determine the effects associated with these chromosomes on important adaptive traits, to investigate the interactions of genes of different genomes and homoeologous groups of cereals, and to reveal allelic relationships between loci located on chromosomes.

Tetraploid species $H$. marinum ssp. gussoneanum $4 x$ belongs to the group of annual cereal plants, is distributed on the eastern coast of the Mediterranean Sea, occupies vast territories of Turkey, Iran, Afghanistan, and is distributed in lowland and foothill regions of Armenia and Central Asia (Bothmer et al. 1991; Jakob et al. 2007). H. marinum inhabits salt marshes and possesses a high degree of tolerance to salinity and swamping (Garthwaite et al. 2005; Islam et al. 2007).

We obtained ditelosomic wheat-barley (T. aestivum-H. marinum ssp. gussoneanum $4 x$ ) substitution lines of the homoeologous group 7 chromosomes (Efremova et al. 2018). The study showed that the lines differ in the heading time during growth in the greenhouse and in the field. Therefore, the study of the allelic composition of the known loci $\mathrm{Vrn}-1$ and $V r n-3$ will make it possible to determine the effect of alien chromosome substitution on heading time.

The aim of this work is to study the effects of alien substitutions of chromosomes on heading time, when grown under controlled conditions and in the field conditions of the forest-steppe zone of the Novosibirsk Region, as well as to establish the allelic composition of the genes $V r n-A 1, V r n-B 1, V r n-D 1$ and $V r n-B 3$ in wheat-alien substitution lines.

\section{Materials and Methods}

\section{Plant material}

The material for the study was wheat-barley (T. aestivum-H. marinum ssp. gussoneanum Hudson $4 x$ ) ditelosomic (DT) substitution lines of the homoeologous group 7 chromosomes (Efremova et al. 2013; Efremova et al. 2018). To obtain substitution lines, the 44-chromosomal ditelosomic addition line $(2 n=44=42+2 \mathrm{t})$ with the telocentric chromosome $7 \mathrm{HL}^{\mathrm{mar}}$ of the wild barley $H$. marinum, derived from common wheat cv. Pyrothrix 28 (Pyr28), was used as the paternal form for pollinating monosomic 7A, 7B and 7D lines of common wheat cv. Saratovskaya 29 (S29) (Efremova et al. 2013). Among the $F_{1}$ hybrids obtained, plants with a chromosome configuration in metaphase 1 (M1) meiosis of $20 "+1$ ' $+\mathrm{t}^{\prime}$ ' were selected. These were self-pollinated, and in $\mathrm{F}_{3-7}$, three wheat-barley DT substituted lines in which the telocentric chromosome $7 \mathrm{HL}^{\text {mar }}$ replaced each of chromosomes 7A, 7B and 7D of wheat were obtained. Nullisomic 7A and 7B $(2 n=40$ or in 
M1 meiosis of 20") plants of common wheat, which were isolated in the hybrid progeny $\mathrm{F}_{3-7}$ during self-pollination of $20^{\prime \prime}+1 '+\mathrm{t}^{\prime}$, were studied. It is known that nullisomics of homoeologous group 7 are notable for increased fertility and viability (Sears 1954).

\section{Growing conditions}

To study the duration of the seedling stage-heading period, DT wheat-barley substitution lines, 7HL ${ }^{\text {mar }}$ addition line, S29, Pyr28 were grown under a short (SD, $12 \mathrm{~h}$ ) and a long day (LD, $16 \mathrm{~h}$ ) in a greenhouse and were planted in the spring of 2015 and 2016 in the experimental field of the Institute of Cytology and Genetics of the SB RAS $\left(55^{\circ} 2.49^{\prime} \mathrm{N}\right.$, $82^{\circ} 56.80^{\prime} \mathrm{E}$, the length of the day for the period from May-August is $17 \mathrm{~h}$ ). The plants were cut on 10-15 September. Thirty plants of each line were studied. The date of heading was recorded for each plant. Statistical processing of the data was carried out using for Student's $t$-test in Microsoft Excel.

\section{DNA isolation and PCR}

Genomic DNA was isolated from the shoots according to a previously described method (Edwards et al. 1991). The known allele-specific primers were used to identify the dominant or recessive alleles of the Vrn-A1, Vrn-B1, Vrn-D1, and Vrn-B3 genes (Table 1).

Table 1. Allele-specific primers used for the analysis of the genotype of wheat-barley substitution lines carrying $V R N$ genes

\begin{tabular}{|c|c|c|c|c|c|c|}
\hline Loci & Allele & Name & Primer $\left(5^{\prime} \rightarrow 3^{\prime}\right)$ & $\begin{array}{l}\text { Expected } \\
\text { product size } \\
\text { (bp) }\end{array}$ & $\begin{array}{c}\text { Annealing } \\
\text { temp. } \\
\left({ }^{\circ} \mathrm{C}\right)\end{array}$ & Reference \\
\hline Vrn-A1 & $\begin{array}{l}\text { Vrn-A1a } \\
\text { Vrn-A1b } \\
v r n-A 1\end{array}$ & $\begin{array}{l}\text { VRN1AF } \\
\text { VRN1R }\end{array}$ & $\begin{array}{l}\text { GAAAGGAAAAATTCTGCTCG } \\
\text { TGCACCTTCCC(C/G)CGCCCCAT }\end{array}$ & $\begin{array}{l}650+750 \\
\quad \approx 480 \\
\quad \approx 500\end{array}$ & 55 & $\begin{array}{l}\text { Yan et al. } \\
2004 ; \\
\text { Fu et al. } \\
2005\end{array}$ \\
\hline Vrn-B1 & $\begin{array}{l}V r n-B 1 a \\
V r n-B 1 c \\
v r n-B 1\end{array}$ & $\begin{array}{l}\mathrm{Ex} 1 / \mathrm{B} / \mathrm{F} 3 \\
\text { Intr1/B/F } \\
\text { Intr1/B/R3 } \\
\text { Intr1/B/R4 }\end{array}$ & $\begin{array}{l}\text { GAAGCGGATCGAGAACAAGA } \\
\text { CAAGTGGAACGGTTAGGACA } \\
\text { CTCATGCCAAAAATTGAAGATGA } \\
\text { CAAATGAAAAGGAATGAGAGCA }\end{array}$ & $\begin{array}{c}709+1235 \\
849 \\
1149\end{array}$ & 58 & $\begin{array}{l}\text { Milec et al. } \\
2012\end{array}$ \\
\hline \multirow[t]{2}{*}{ Vrn-D1 } & Vrn-D1 & $\begin{array}{l}\text { Intr1/D/F } \\
\text { Intr1/D/R3 }\end{array}$ & $\begin{array}{l}\text { GTTGTCTGCCTCATCAAATCC } \\
\text { GGTCACTGGTGGTCTGTGC }\end{array}$ & 1671 & 61 & \multirow{2}{*}{$\begin{array}{l}\text { Yan et al. } \\
2004 \\
\text { Fu et al. } \\
2005\end{array}$} \\
\hline & vrn-D1 & $\begin{array}{l}\text { Intr1/D/F } \\
\text { Intr1/D/R4 }\end{array}$ & $\begin{array}{l}\text { GTTGTCTGCCTCATCAAATCC } \\
\text { AAATGAAAAGGAACGGAGCG }\end{array}$ & 997 & 56 & \\
\hline \multirow[t]{2}{*}{ Vrn-B3 } & $V r n-B 3$ & $\begin{array}{l}\text { VRN4-B- } \\
\text { INS-F } \\
\text { VRN4-B- } \\
\text { INS-R }\end{array}$ & $\begin{array}{l}\text { CATAATGCCAAGCCGGTGAGTAC } \\
\text { ATGTCTGCCAATTAGCTAGC }\end{array}$ & $\approx 1200$ & 63 & \multirow[t]{2}{*}{$\begin{array}{l}\text { Yan et al. } \\
2006\end{array}$} \\
\hline & $v r n-B 3$ & $\begin{array}{l}\text { VRN4-B- } \\
\text { NOINS-F } \\
\text { VRN4-B- } \\
\text { NOINS-R }\end{array}$ & $\begin{array}{l}\text { ATGCTTTCGCTTGCCATCC } \\
\text { CTATCCCTACCGGCCATTAG }\end{array}$ & $\approx 1140$ & 57 & \\
\hline
\end{tabular}


Amplification of DNA was carried out according to the protocols proposed by the authors. The nucleotide sequences of the primers are shown in Table 1. The amplification products were separated by electrophoresis in a $1.5 \%$ agarose gel in $1 \times$ TAE buffer. The gels were stained with ethidium bromide and photographed in ultraviolet light.

\section{Results}

The study of the duration of the period from seedling stage to heading in wheat-barley ditelosomic substitution lines for chromosomes of homoeologous group 7

The influence of alien substitution of the barley $H$. marinum chromosome $7 \mathrm{HL}^{\text {mar }}$ with chromosomes 7A, 7B and 7D of common wheat on the period from seedling stage to heading during growth under LD and SD conditions was studied. Under the conditions of LD (16 h), DT7HL ${ }^{\operatorname{mar}}$ (7B) and DT7HL ${ }^{\operatorname{mar}}$ (7D) were the most late-maturing, with heading dates occuring on day 51 . The heading date of the line DT7HL ${ }^{\operatorname{mar}}(7 \mathrm{~A})$ was earlier on day 46 (Table 2). At the same time, significant differences in the heading date were established only between DT7HL ${ }^{\operatorname{mar}}(7 \mathrm{~A})$ and DT7HL ${ }^{\operatorname{mar}}(7 \mathrm{~B})$, and the difference between the

Table 2. The effect of genotype and length of the day on the heading time of substitution lines in the greenhouse and field

\begin{tabular}{|c|c|c|c|c|c|}
\hline \multirow{3}{*}{$\begin{array}{l}\text { Genotype and estimates of } \\
\text { genetic difference }\end{array}$} & \multirow{3}{*}{$\begin{array}{c}\text { Photoper. } \\
\text { sens }^{1}\end{array}$} & \multicolumn{4}{|c|}{ Seedling stage - heading time (days) } \\
\hline & & \multicolumn{2}{|c|}{ Greenhouse } & \multicolumn{2}{|c|}{ Field } \\
\hline & & $12 \mathrm{~h}$ & $16 \mathrm{~h}$ & 2015 & 2016 \\
\hline $\mathrm{DT} \mathrm{HL}^{\operatorname{mar}}(7 \mathrm{~A})(\mathrm{A})$ & $5.56^{\#}$ & $51.75 \pm 1.73$ & $46.19 \pm 1.83$ & $48.35 \pm 2.05$ & $48.96 \pm 1.65$ \\
\hline DT7HL ${ }^{\operatorname{mar}}(7 \mathrm{~B})(\mathrm{B})$ & $12.44^{\#}$ & $64.19 \pm 3.75$ & $51.75 \pm 3.95$ & - & $52.93 \pm 3.47$ \\
\hline $\mathrm{DT}_{\mathrm{HHL}}^{\operatorname{mar}}(7 \mathrm{D})(\mathrm{D})$ & 2.67 & $53.67 \pm 1.33$ & $51.0 \pm 3.39$ & $49.39 \pm 3.01$ & $52.0 \pm 0.82$ \\
\hline nulli7A (C) & $7.54^{\# \#}$ & $48.08 \pm 1.95$ & $40.54 \pm 1.67$ & - & $51.83 \pm 1.47$ \\
\hline nulli7B (F) & $19.19^{\# \# \# ~}$ & $65.80 \pm 4.84$ & $46.61 \pm 1.93$ & $58.58 \pm 3.49$ & $56.63 \pm 1.85$ \\
\hline Saratovskaya $29(\mathrm{G})$ & 0.2 & $34.5 \pm 0.90$ & $34.3 \pm 0.67$ & $40.49 \pm 1.78$ & 43. \pm 0.97 \\
\hline Pyrothrix $28(\mathrm{H})$ & 1.2 & $40.0 \pm 0.78$ & $41.2 \pm 0.73$ & $50.69 \pm 2.65$ & $51.58 \pm 2.65$ \\
\hline 7HL $\mathrm{HLr}^{\mathrm{mar}}$ addition line $(\mathrm{I})$ & 1.29 & $40.02 \pm 1.17$ & $41.31 \pm 0.97$ & $50.0 \pm 2.69$ & $52.12 \pm 1.83$ \\
\hline H. marinum & & - & $57 \pm 3.51$ & - & - \\
\hline Difference (A-B) & & $-12.44 * *$ & $-5.56^{*}$ & - & -3.97 \\
\hline Difference $(\mathrm{A}-\mathrm{D})$ & & -1.92 & -4.81 & -1.04 & -3.04 \\
\hline Difference (B-D) & & $10.52 * *$ & 0.75 & - & 0.93 \\
\hline Difference $(\mathrm{C}-\mathrm{F})$ & & $-17.72 * * *$ & $-6.07 *$ & - & $4.8^{*}$ \\
\hline Difference $(\mathrm{G}-\mathrm{H})$ & & $-5.5 * * *$ & $-6.96 * * *$ & $-10.2 * * *$ & $-7.78 * *$ \\
\hline Difference $(\mathrm{H}-\mathrm{I})$ & & -0.02 & -0.11 & -0.69 & -0.54 \\
\hline
\end{tabular}

$*$ Difference is significant at $* \mathrm{p}<0.05 . * \mathrm{p}<0.01 . * * * \mathrm{p}<0.001$.

${ }^{1}$ Photoperiod sensitivity was determined as the difference in heading time measured under the 12 and $16 \mathrm{~h}$ photoperiod regimes. ${ }^{\mathrm{p}}<0.05$. ${ }^{\#} \mathrm{p}<0.01 . \# \mathrm{p}<0.001$. 
lines was 5 days. Analogous results were also obtained in the study of nullisomics 7A and $7 \mathrm{~B}$; the heading date of nulli7B occurred later by 6 days. Consequently, the late ripeness of the DT7HL ${ }^{\operatorname{mar}}(7 \mathrm{~B})$ line may be due to the lack of chromosome $7 \mathrm{~B}$. Under these conditions, S29 and Pyr28 were more early-ripening than the substitution lines and heading date occurred on 34 and 41 days, respectively. At the same time, S29 was more earlyripening, and the difference in the heading date between S29 and Pyr28 was more than 6 days. The heading date of addition line with the chromosome $7 \mathrm{HL}^{\text {mar }}$ did not differ from Pyr28. The growing season of $H$. marinum is long, as demonstrated by the late-ripening forms of common wheat: in the conditions of a greenhouse from sprouting to heading, it is 55-70 days. The entire growing season is 90-110 days.

Under the conditions of SD (12 h), all DT lines showed an extension of the growing season, but the strongest effect on the increase in the period before heading was 12 days in the DT7HL ${ }^{\operatorname{mar}}$ (7B) line (Table 2). The effect for the DT7HL ${ }^{\operatorname{mar}}$ (7A) line was less than 5 days, and for the DT7HL ${ }^{\operatorname{mar}}$ (7D) line, it was approximately 3 days. The differences in heading time differed significantly only between DT7HL ${ }^{\operatorname{mar}}$ (7A) and DT7HL ${ }^{\operatorname{mar}}(7 \mathrm{~B})(12$ days) and between DT7HL ${ }^{\operatorname{mar}}$ (7B) and DT7HL ${ }^{\operatorname{mar}}$ (7D) (10 days). The effect of the absence of chromosomes 7A and 7B on the heading time is also confirmed in the study of nullisomics for these chromosomes. Under SD conditions, the heading date of nulli7A occurred seven days later and for nulli7B, 19 days later. The difference between nullisomics was approximately 18 days. Consequently, under SD conditions, photoperiodic sensitivity appears, which leads to an increase in the period before heading. In this case, the strongest effect is associated with chromosome 7B carrying the known Ppd-B2 gene; chromosome 7A has the next strongest influence. At the same time, the absence of chromosome 7D has practically no effect on the heading time of DT lines when grown under conditions of LD and SD. In S29, Pyr28 and the 7HL ${ }^{\text {mar }}$ addition line, the length of the seedling stage-heading period under SD conditions did not virtually differ from the LD conditions. The heading time of Pyr28 and the $7 \mathrm{HL}^{\text {mar }}$ addition line occurred on 40 day. This may indicate that the $7 \mathrm{HL}^{\text {mar }}$ chromosome does not affect the length of the period before heading.

Under the natural LD conditions of Western Siberia in the field, the DT lines did not differ significantly in the heading time (Table 2). At the same time, the DT7HL ${ }^{\text {mar }}$ (7A) line (48 days) had earlier heading time. Under these conditions, DT7HL ${ }^{\operatorname{mar}}(7 \mathrm{~B})$ and DT7HL $^{\operatorname{mar}}$ (7D) were virtually indistinguishable in the duration of the period before heading (52 days). In natural field conditions, the nulli7B heading occurred on day 57, 5 days later than in nulli7A.

Under field conditions, S29 was more early-ripening and heading time occurred on 8-10 days earlier than Pyr28. The differences in the length of the seedling stage-heading period were not found between the $7 \mathrm{HL}^{\mathrm{mar}}$ addition line and Pyr28.

\section{Allelic combination of vernalization genes}

The second aim of our study was to determine the genotype of the studied lines for the $V r n$ genes, which, similar to the Ppd genes, affect the duration of the growing season. To 

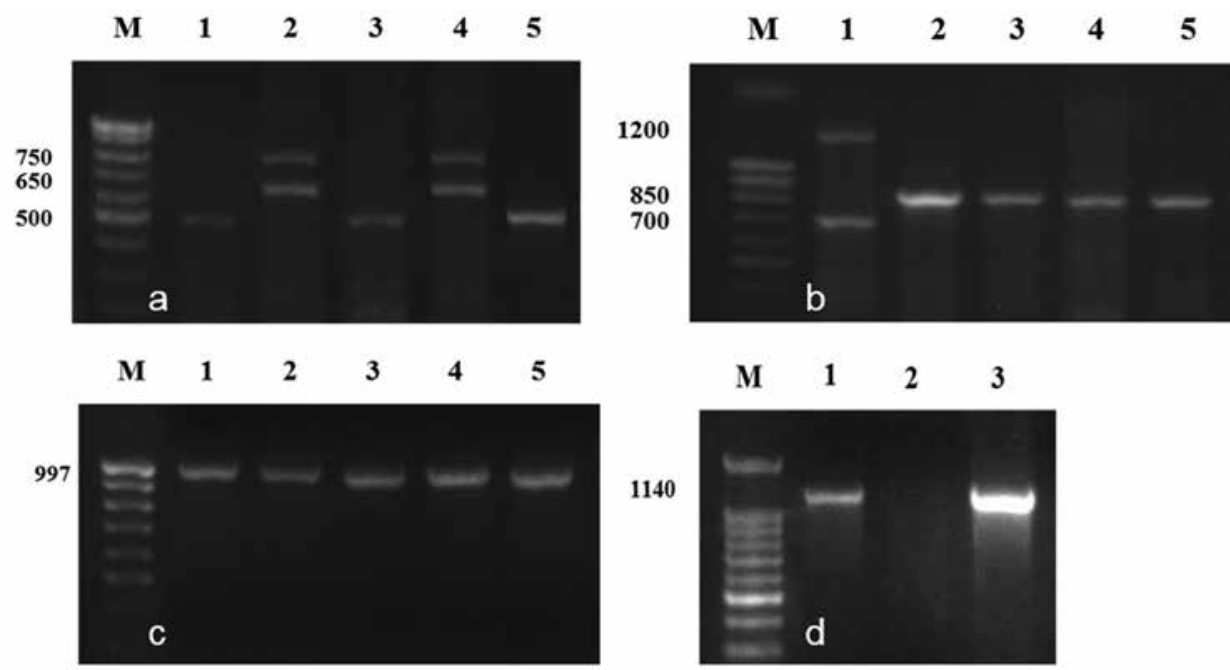

Figure 1. Using allele-specific primers for the identification of $V r n$ genes in DT wheat-barley substitution lines: $V r n-A 1$ (a), Vrn-B1 (b), vrn-D1 (c), vrn-B3 (d). a: Vrn-Ala - 650 и 750 bp, vrn-A1 и Vrn-A1b - 500 bp (difference of 20 bp); b: Vrn-B1a - 700 и 1200 bp, Vrn-B1c - 850 bp; c: vrn-D1 - 997 bp; d - vrn-B3 - 1140 bp. a, b, c: 1 - Pyr28, 2 - S29, 3 - DT7HL ${ }^{\operatorname{mar}}$ 7A), 4 - DT7HL ${ }^{\operatorname{mar}}$ (7B), 5 - DT7HL ${ }^{\operatorname{mar}}$ (7D); d: 1 - DT7HL ${ }^{\text {mar }}$ (7A), 2 - DT7HL ${ }^{\operatorname{mar}}(7 \mathrm{~B}), 3$ - DT7HL ${ }^{\operatorname{mar}}$ (7D)

do this, a study of the allelic diversity of the known Vrn-1 and Vrn-3 loci localized on chromosomes of homeologous groups 5 and 7 using allele-specific primers was performed (Fig. 1). The DT7HL ${ }^{\operatorname{mar}}$ (7A), DT7HL ${ }^{\operatorname{mar}}$ (7D) lines and Pyr28 carry the $V r n-A 1 b$ allele (a 500 bp fragment was amplified). The DT7HL ${ }^{\operatorname{mar}}(7 \mathrm{~B})$ line and S29 had a $\mathrm{Vrn}-\mathrm{Ala}$ allele (two 650 and $750 \mathrm{bp}$ fragments were amplified). It was found that all three lines carry the dominant $\mathrm{Vrn}-\mathrm{B} 1 \mathrm{c}$ allele (850 bp fragment). The $1040 \mathrm{bp}$ fragment, which is specific to the recessive allele of the $v r n-B 3$ gene, was amplified in lines with the substitution of 7A and 7D chromosomes. In the line lacking the 7B chromosome of wheat, no amplification fragments of the corresponding length specific for the markers used were found.

Thus, based on the results obtained, it is established that wheat-barley lines differ in different alleles of the dominant $V r n-A 1$ gene. Two DT7HL ${ }^{\operatorname{mar}}$ (7A) and DT7HL ${ }^{\text {mar }}$ (7D) lines have the same genotype for the $V r n-V R N-A 1 b / V R N-B 1 c / v r n-D / v r n-B 3$ genes. The DT7HL $^{\operatorname{mar}}(7 \mathrm{~B})$ line has the $V R N-A 1 a / V R N-B 1 c / v r n-D 1$ genotype.

\section{Discussion}

In this paper, we studied the effects of alien chromosome substitution on the DT heading time of wheat-barley substitution lines in which the $7 \mathrm{HL}^{\text {mar }}$ chromosome from $\mathrm{H}$. marinum replaced wheat chromosomes 7A, 7B and 7D. Chromosomes belonging to this group carry genes that affect the heading time of common wheat and cultivated barley. In barley 
(Hordeum vulgare L.), the Vrn-H3 gene is located on chromosome 7HS (Yan et al. 2006). As a result, a study of a series of wheat-barley addition lines showed the effect of $7 \mathrm{H}$ chromosomes on heading time (Farkas et al. 2014). The addition line with chromosome $7 \mathrm{H}$ was earlier maturing under different growth conditions, which may be due to the addition of an additional copy of the barley $\mathrm{Vrn}-\mathrm{H3}$ gene to the $\mathrm{Vrn} 3$ gene series of wheat (Farkas et al. 2014). It is interesting to note that the effect of adding $7 \mathrm{H}$ also depended on the genetic background of wheat.

In wheat, the $V r n-B 3$ gene (formerly known as $V r n 5$ or $V r n-B 4$ ), localized on chromosome 7BS, was first identified in a substituted line Chinese Spring/Hope 7B (Law and Worland 1997; Yan et al. 2006). Furthermore, the dominant Vrn-B3 gene was found in local samples from the Southeast region and in several cultivars from China (Yan et al. 2006; Chen et al. 2013). The Vrn-B3 gene is the orthologue of the Arabidopsis FLOWERINGLOCUS T (FT) gene and has homology with the Vrn-A3 and Vrn-D3 genes located on chromosomes 7AS and 7DS (Yan et al. 2006; Bonnin et al. 2008). It was shown that $V R N$ $H 3$, mapped on chromosome 7HS of $H$. vulgare, is collinear with $V R N-B 3$. Diagnostic markers were developed to determine the dominant and recessive alleles of the $\mathrm{Vrn}-\mathrm{B} 3$ gene (Yan et al. 2006).

In our work, the dominant allele of the $\mathrm{Vrn}-\mathrm{B} 3$ gene was not detected in the substituted lines. The lines carry a recessive allele of $v r n-B 3$ and the DT7HL ${ }^{\operatorname{mar}}(7 \mathrm{~B})$ line lacked amplification fragments specific for $V r n-B 3$ gene markers. The dominant allele of the $V r n-B 3$ gene was not detected in the parent cultivars Sar29 and Pyr28. It is possible that among the Russian wheat cultivars, this gene is not widely distributed; it is hoped that the use of DNA markers will clarify this issue. In the studied lines, the presence of two combinations of the dominant alleles $-V R N-A 1 a / V R N-B 1 c$ and $V R N-A 1 b / V R N-B 1 c$ and the recessive allele $v r n-D 1$ was revealed. Many researchers have established that contemporary cultivars carrying these allele combinations are the most common worldwide and determine the early maturity of wheat plants (Fu et al. 2004; Zhang et al. 2008).

Our work showed that wheat-barley lines, irrespective of the genotype for the Vrn genes, react to the change in the photoperiod. It was established earlier that the initial parent cultivars S29 and Pyr28, as well as the substituted lines, carry one dominant Ppd-A1 gene on chromosome 2A (Aliev and Maystrenko 1986), which determines insensitivity to the photoperiod. Since the lines studied have the same genotype for the Ppdl genes, it can be assumed that the differences in the photoperiod response are associated with genes located on the chromosomes of homoeologous group 7. As a result of a comparative study of the lines, it was shown that photoperiodic sensitivity, which manifests under SD conditions, leads to an increase in the period before heading in DT7 HL ${ }^{\operatorname{mar}}(7 \mathrm{~B})$ and DT7HL ${ }^{\mathrm{mar}}(7 \mathrm{~A})$ lines.

At the same time, the effect of chromosome 7B was more significant than the effect of chromosome 7A. Substitution of chromosome 7D had no significant effect on heading time. Under LD conditions in the greenhouse and under natural conditions, the lines come into ear earlier than under SD conditions and do not differ among themselves. Such a genotype response to the length of the day may be due to the lack of a chromosome $7 \mathrm{~B}$ in which the Ppd-B2 gene is localized (Khlestkina et al. 2009). The probability of the pres- 
ence of a second homeoallele set of genes for photoperiodic response, which are localized on the chromosomes of homoeologous group 7, was shown by Kuchel et al. (2006), QTL for photoperiod sensitivity were detected on chromosomes 7AS and 7BS, and on chromosome 7HS of barley (Börner et al. 2002). The role of homeologous group 7 chromosomes in the response to day length was shown in studies of lines with inter-varietal chromosomal substitution, such as Chinese Spring/ Hope (Halloran and Boydell 1967), and monosomic analysis, such as in a combination of mono Cheyenne $\times$ Sonora 64 (Pirasteh and Weish 1975). In these works, a hypothesis was made about the presence of a weak dominant gene on chromosome $7 \mathrm{~B}$.

Summing up the results of a comparative study of the DT lines heading time, it can be concluded that the absence of the 7B chromosome under SD conditions leads to an increase in the period before heading. Secondary to the effect on the length of the day may be a gene located on chromosome 7A. Chromosome 7D does not affect the heading time of the studied DT lines, both in the field and in the greenhouse under the conditions of SD and LD. In our experiment, the effect of the long arm of $H$. marinum chromosome $7 \mathrm{H}$ on heading time was not observed, and the main differences in the trait studied are associated with the chromosomes of homoeologous group 7 of wheat. It is hoped that the obtained lines will be used as a basis for studying the interactions between the chromosomes of two species, affecting a number of traits, in addition to heading.

\section{Acknowledgements}

This research was supported by the Russian Foundation for Basic Research (17-0400721_a) and budgetary project 0324-2019-0039.

\section{References}

Aliev, E.B., Maystrenko, O.I. 1986. A precise determination of number of genes involved in photoperiodic response in spring wheats with different sensitivity to natural short day light. Cereal Res. Commun. 14:129-131.

Beales, J., Turner, A., Griffiths, S., Snape, J.W., Laurie, D.A. 2007. A pseudo-response regulator is misexpressed in the photoperiod insensitive Ppd-Dla mutant of wheat (Triticum aestivum L.). Theor. Appl. Genet. 115:721-733.

Bothmer, R., Jacobsen, N., Baden C., Jorgensen, R., Linde-Laursen, I. 1991. An ecogeographical study of the genus Hordeum. IBPGR, 1991. Italy, Rome, 127 p.

Bonnin, I., Rousset, M., Madur, D., Sourdille, P., Dupuits, C., Brunel, D., Goldringer, I. 2008. FT genome A and D polymorphisms are associated with the variation of earliness components in hexaploid wheat. Theor. Appl. Genet. 116:383-394.

Börner, A., Buck-Sorlin, G.H., Hayes, P.M., Malyshev, S., Korzun, V. 2002. Molecular mapping of major genes and quantitative trait loci determining flowering time in response to photoperiod in barley. Plant Breed 121:129-132. doi:10.1046/j.1439-0523.2002.00691.x.

Cane, K., Eagles, H.A., Laurie, D.A., Trevaskis, B., Vallance, N., Eastwood, R.F., Gororo, N.N., Kuchel, H., Martin, P.J. 2013. Ppd-B1 and Ppd-D1 and their effects in southern Australian wheat. Crop and Pasture Science. 64:100-114.

Ceoloni, C., Jauhar, P.P. 2006. Chromosome engineering of the durum wheat genome: strategies and applications of potential breeding value. In: Singh, R.J., Jauhar P.P. (eds) Genetic resources, chromosome engineering, and crop improvement: cereals. Boca Raton, FL: CRC Press, Taylor \& Francis Group, pp. 27-59. 
Chen, F., Gao, M., Zhang, J., Zuo, A., Shang, X., Cui, D. 2013. Molecular characterization of vernalization and response genes in bread wheat from the Yellow and Huai Valley of China. BMC Plant Biol. 13:199.

Edwards, K., Johnstone, C., Thompson, C. 1991. A simple and rapid method for the preparation of plant genomic DNA for PCR Analysis. Nucl. Acids Res. 19:1349.

Efremova, T.T., Maystrenko, O.I., Arbuzova, V.S., Laikova, L.I., Panina, G.M., Popova, O.M., Berezova, O.V. 2006. Effect of alien 5R(5A) chromosome substitution on ear-emergence time and winter hardiness in wheat-rye substitution lines. Euphytica 151:145-153.

Efremova, T.T., Arbuzova, V.S., Leonova, I.N., Makhmudova, K. 2011. Multiple allelism in the Vrn-B1 locus of common wheat. Cereal Res. Comm. 39(1):12-21.

Efremova, T., Arbuzova,V., Trubacheeva, N., Ocadchaya, T., Chumanova, E., Pershina, L. 2013. Substitution of Hordeum marinum ssp. gussoneanum chromosome 7HL into wheat homoeologous group-7. Euphytica 192:251-257.

Efremova, T.T., Chumanova, E.V., Trubacheeva, N.V., Pershina, L.A. 2018. Compensation ability between the chromosomes of homoeologous group 7 of Triticum aestivum L. and Hordeum marinum ssp. gussoneanum Hudson $(2 n=28)$ and analysis of the transmission frequency of alien $7 \mathrm{H}^{1} \mathrm{~L}^{\text {mar }}$ chromosome through gametes in the progeny of wheat-barley substitution lines. Russ. J. Genet. 54:1050-1058.

Farkas, A., Molnár, I., Kiss, T., Karsai, I., Molnár-Láng, M. 2014. Effect of added barley chromosomes on the flowering time of new wheat/winter barley addition lines in various environments. Euphytica 195:45-55.

Fu, D., Szucs, P., Yan, L., Helguera, M., Skinner, J.S., von Zitzewitz, J., Hayes, P.M., Dubcovsky, J. 2005. Large deletions within the first intron in $V R N-1$ are associated with spring growth habit in barley and wheat. Mol. Gen. Genomics 273:54-65.

Garthwaite, A.J., Von Bothmer, R., Colmer, T.D. 2005. Salt tolerance in wild Hordeum species associated with restricted entry of $\mathrm{Na}^{+}$and $\mathrm{Cl}^{-}$into the shoots. J. Exp. Bot. 56:2365-2378.

Guo, Z., Song, Y., Zhou, R., Ren, Z., Jia, J. 2010. Discovery, evaluation and distribution of haplotypes of the Ppd-Dl gene. New Phytol. 185:841-851.

Halloran, G.H., Boydell, C.W. 1967. Wheat chromosomes with genes for photoperiodic response. Can. J. Genet. Cytol. 22:394-398.

Islam, S., Malik, A.I., Islam, A.K.M.R., Colmer, T.D. 2007. Salt tolerance in a Hordeum marinum-Triticum aestivum amphiploid, and its parents. J. Exper. Botany 58:1219-1229.

Jakob, S.S., Ihlow, A., Blattner, F.R. 2007. Combined ecological niche modelling and molecular phylogeography revealed the evolutionary history of Hordeum marinum (Poaceae)-niche differentiation, loss of genetic diversity, and speciation in Mediterranean Quaternary refugia. Molecular Ecology 16:1713-1727.

Khlestkina, E.K., Giura, A., Röder, M.S., Börner, A. 2009. A new gene controlling the flowering response to photoperiod in wheat. Euphytica 165:579-585.

Kuchel, H., Hollamby, G., Langridge, P., Williams, K., Jefferies, S.P. 2006. Identification of genetic loci associated with ear emergence in bread wheat. Theor. Appl. Genet. 113:1103-1112.

Law, C.N. 1972. The analysis of inter-varietal chromosome substitutions in wheat and their first generation hybrids. Heredity 28:169-179.

Law, C.N., Worland, A.J., Giorgi, B. 1976. The genetic control of ear emergence by chromosomes 5A and 5D of wheat. Heredity 36:49-58.

Law, C.N., Sutka, J., Worland, A.J. 1978. A genetic study of day-length response in wheat. Heredity 41:185191.

Law, C.N., Worland, A.J. 1997. Genetic analysis of some flowering time and adaptative traits wheat. New Phytologist 137:19-28.

Milec, Z., Tomková, L., Sumíová, T., Pánková, K. 2012. A new multiplex PCR test for the determination of Vrn-B1 alleles in bread wheat (Triticum aestivum L.). Mol. Breeding 30:317-323.

Murai, K., Koba, T., Shimada, T. 1997. Effect of barley chromosome on heading characters in wheat-barley chromosome addition lines. Euphytica 96:281-287.

Pirasteh, B., Welsh, J.R. 1975. Monosomic analysis of photoperiod response in wheat. Crop. Sci. 15:503-0505.

Qi, L.L., Friebe, B., Zhang, P., Gill, B.S. 2007. Homoeologous recombination, chromosome engineering and crop improvement. Chromosome Res. 15:3-19. 
Scherban, A.B., Efremova, T.T., Salina, E.A. 2012. Identification of a new Vrn-B1 allele using two near-isogenic wheat lines with difference in heading time. Mol. Breeding 29:675-685.

Sears, E.R. 1954. The aneuploids of common wheat. Research Bulletin Missouri Agricultural Experiment Station. 572:1-59.

Snape, J.W., Law, C.N., Parker, B.B., Worland, A.J. 1985. Genetical analysis of chromosome 5A of wheat and its influence on important agronomic characters. Theor. Appl. Genet. 71:518-526.

Snape, J.W., Butterworth, K., Whitechurch, E., Worland, A.J. 2001. Waiting for fine times: genetics of flowering time in wheat. Euphytica 119:185-190.

Worland, A.J., Börner, A., Korzun, V., Li, W.M., Petrovic, S., Sayers, E. J. 1998. The influence of photoperiod on the adaptability of European winter wheats. Euphytica 100:385-394.

Yan, L., Helguera, M., Kato, K., Fukuyama, S., Sherman, J., Dubcovsky, J. 2004. Allelic variation at the $V R N-1$ promoter region in polyploid wheat. Theor. Appl. Genet. 109:1677-1686.

Yan, L., Fu, D., Li, C., Blechl, A., Tranquilli, G., Bonafede, M., Sanchez, A., Valarik, M., Yasuda, S., Dubcovsky, J. 2006. The wheat and barley vernalization gene VRN3 is an orthologue of FT. Proc. Natl. Acad. Sci. USA. 103:19581-19586.

Yoshida, T., Nishida, H., Zhu, J., Nitcher, R., Distelfeld, A., Akashi, Y., Kato, K., Dubcovsky, J. 2010. Vrn-D4 is a vernalization gene located on the centromeric region of chromosome $5 \mathrm{D}$ in hexaploid wheat. Theor. Appl. Genet. 120:543-552.

Zhang, X.K., Xia, X.C., Xiao, Y.G., Dubcovsky, J., He, Z.H. 2008. Allelic variation at vernalization genes Vrn$A 1, V r n-B 1, V r n-D 1$ and $V r n-B 3$ in Chinese common wheat cultivars and their association with growth habit. Crop Sci. 48:458-470.

Zhang, J., Wang, Y., Wu, S., Yang, J., Liu, H., Zhou, Y. 2012. A single nucleotide polymorphism at the Vrn-D1 promoter region in common wheat is associated with vernalization response. Theor. Appl. Genet. 125:16971704. 